\title{
NEONATAL THYMECTOMY: DOES IT AFFECT IMMUNE FUNCTION?
}

Winfield J. Wells, MD

Robertson Parkman, MD

Elizabeth Smogorzewska, MD

Mark Barr, MD
Objective: The purpose of this study was to determine whether thymectomy in the newborn has a negative effect on immune function. Methods: Twenty-five neonates ( $<30$ days) who had thymectomy at congenital heart repair were prospectively studied to determine immune function. The percentage of T-cell subtypes including CD3 (all T cells), CD4 (helper T cells), and CD8 (suppressor $T$ cells) was determined. In six patients, further testing of CD4 cells was done to determine whether they were newly formed, recent thymic emigrants (CD4, CD45, and $\mathrm{RA}^{+}$), or older educated lymphocytes (CD4, CD45, and $\left.\mathrm{RO}^{+}\right)$. Response to the mitogen phytohemagglutinin and to tetanus toxoid were determined, as were antibody titers to tetanus. Samples were drawn before the thymectomy, at approximately 3 months after immunization and at 1 year. Ten age-matched control patients were tested. At follow-up, parents were asked about infections. Results: Prethymectomy T-cell subsets were all normal and comparable to controls. At 12 months, the percent of CD3 was significantly less than in the control group $(48 \% \pm 3 \%$ versus $64 \% \pm 2 \%$ [mean \pm standard error of the mean]; $p<0.01)$ as was CD4 $(31 \% \pm 2 \%$ versus $46 \%+2 \%$ [mean \pm standard error of the mean]; $p=<0.01)$. CD8 did not drop. Surprisingly, the percent of CD4 that were recent thymic emigrants did not decrease significantly $(50 \%$ $\pm 8 \%$ versus $60 \% \pm 6 \%$ [mean \pm standard error of the mean]; $p=$ not significant). Lymphocyte blastogenesis to phytohemagglutinin and tetanus toxoid and antibody to tetanus were all normal at 12 months. No patient required readmission for infection, and there were the expected number of minor infectious events (median 3; 95\% confidence interval 1,4). Conclusion: Thymectomy in neonates results in a modest but significant decrease in T-lymphocyte levels, but there is no compromise in immune function. (J Thorac Cardiovasc Surg 1998;115:1041-6)
In the newborn, thymectomy facilitates cannulation for cardiopulmonary bypass and exposure for mobilization or reconstructing of the aortic arch. Although thymectomy in children who are younger than 6 months of age and adults has been shown to

From the Division of Cardiothoracic Surgery, Childrens Hospital, Los Angeles, Calif.

Read at the Seventy-seventh Annual Meeting of The American Association for Thoracic Surgery, Washington, D.C., May 4-7, 1997.

Received for publication May 6, 1997; revisions requested June 30, 1997; revisions received Dec. 29, 1997; accepted for publication Dec. 29, 1997.

Address for reprints: Winfield J. Wells, MD, Associate Professor of Surgery, Division of Cardiothoracic Surgery, Childrens Hospital Los Angeles, 4650 Sunset Blvd., MS 66, Los Angeles, CA 90027.

Copyright (C) 1998 by Mosby, Inc.

$0022-5223 / 98 \$ 5.00+0 \quad \mathbf{1 2 / 6 / 8 8 6 8 5}$ be tolerated without compromise of the immune system, ${ }^{1,2}$ there is very little information on the impact of neonatal thymectomy. The only published report specifically addressing this issue suggests avoiding thymectomy in infants younger than 3 months of age because of evidence of impaired immunity as tested in later childhood. ${ }^{3}$ To further investigate this issue, we have prospectively studied a group of neonates who underwent thymectomy at the time of cardiopulmonary bypass in the first month of life.

\section{Patients and methods}

Demographics. Twenty-five neonates ( $<30$ days of age) who had undergone thymectomy at an operation for congenital heart disease were prospectively entered into the study. The anatomic diagnosis of heart disease present in the study patients is documented in Table I. Control values for tests of immune function were determined in 10 age-matched (3 to 12 months of age) patients who had not 
Table I. Congenital heart defects in study

\begin{tabular}{lc}
\hline & Patients \\
\hline Transposition of the great vessels & 13 \\
Total anomalous pulmonary venous connection & 5 \\
Truncus arteriosus & 1 \\
Aortic stenosis & 2 \\
Pulmonary atresia & 1 \\
Hypoplastic left heart syndrome & 3 \\
\hline
\end{tabular}

undergone thymectomy. No study or control patient carried the diagnosis of DiGeorge syndrome or asplenia.

Cell sources. Peripheral blood samples were drawn from study patients before thymectomy, at approximately 3 months of age (after the first immunization), and at 1 year of age. Three milliliter specimens were collected in sterile tubes containing heparin at the time of routine blood sampling and processed within 24 hours. Control patients had a single sample analyzed.

Immune system testing. Studies performed to evaluate the immune system are summarized in Table II. T-cell immunophenotyping was performed by staining with fluorescein-labeled monoclonal antibodies to lymphocyte surface antigens CD2, CD3, CD4, and CD8. In addition, in some patients further testing of CD4 cells was performed to determine whether they were newly formed, naive lymphocytes of recent thymic origin (CD4, CD45, and $\mathrm{RA}^{+}$) or older, educated memory lymphocytes (CD4, $\mathrm{CD} 45$, and $\left.\mathrm{RO}^{+}\right)$. CD45 is a glycoprotein surface antigen having the two isoforms, RA and RO.

In vitro mitogenic response was evaluated by culturing lymphocytes for 3 days with phytohemagglutinin (PHA; Difco Labs). The cells were stimulated with three concentrations $(100 \mu \mathrm{g} / \mathrm{ml}, 20 \mu \mathrm{g} / \mathrm{ml}$, and $4 \mu \mathrm{g} / \mathrm{ml})$, and results were expressed as the maximum proliferation. PHA was pulsed on day 3 and cells were harvested on day 4. Blastogenesis transformation of T lymphocytes was determined by tritiated thymidine incorporation and expressed as counts per minute ( $\mathrm{cpm}$ ) after subtracting background counts (experiment minus control). The standard in our laboratory is to report experiment minus control rather than stimulation index because, unless control blastogenesis is consistent, variations of control counts per minute will have an inappropriate and misleading effect on the results. Normal values as determined from the Clinical Immunology Laboratory at Childrens Hospital Los Angeles were considered to be greater than $75 \times 10^{3} \mathrm{cpm}$. This value has been determined by testing the response of a large number of control individuals.

Antigenic-specific in vitro responses were tested by stimulating lymphocytes for 6 days in the presence of tetanus toxoid (Massachusetts Biological Laboratory, Boston, Mass.). Tetanus toxoid has been shown to have a very flat dose-response curve so that, in our laboratory, multiple concentration testing is not performed. Our standard concentration of tetanus toxoid is 1:1000. Tetanus was pulsed on day 6 , and cell harvesting took place on day 7. Normal values were considered to be greater than $3 \times 103 \mathrm{cpm}$ (background subtracted). This lower limit and the lower limit for antibody titer to tetanus toxoid have been determined by testing the response of a large
Table II. Tests of immune function

Percent of T lymphocytes with immunophenotype CD3, CD4, $\mathrm{CD} 8, \mathrm{CD} 4 \mathrm{CD} 45 \mathrm{RO}+, \mathrm{CD} 4 \mathrm{CD} 45 \mathrm{RA}+$

Lymphocyte blastogenesis reaction to PHA and tetanus toxoid Antibody titer to tetanus toxoid

number of control individuals in our laboratory at Childrens Hospital Los Angeles.

To measure T-cell to B-cell cooperation, antibody titer to tetanus toxoid was measured. A value of greater than 0.1 IU was considered normal. Antibody levels were determined by use of an enzyme-linked immunosorbent assay and standardized by use of a reference antiserum with a known concentration of antibody quantified in international units.

Follow-up. Study patients were followed for at least 1 year. Hospital charts were reviewed to determine whether there had been an admission for infection or whether infections had been noted at the time of outpatient visits. At the 3- and 12-month blood testing interval, families were questioned about history of infection. The incidence of infection was compared with measures of immune function to determine whether there was any correlation.

Statistical analysis. The significance of differences between means in laboratory indices was determined by use of the Student $t$ test when the data were normally distributed. Student Equal Variance $t$ test and Aspen Welch Unequal Variance test were used when appropriate. When the data were skewed, Wilcoxon rank sum tests or Mann-Whitney U (for ties) was applied. The Spearman rank correlation coefficient was used as a measure of association when one or both variables were skewed. Skewness and kurtosis was based on the omnibus normality test statistic.

\section{Results}

T-cell subsets. After thymectomy, patients had a lower proportion of lymphocytes with the surface antigens CD3 (all T cells), CD4 (helper T cells), and CD8 (suppressor/cytotoxic T cells). These changes were most marked at 12 months (Table III).

Comparing prethymectomy values or control values for $\mathrm{CD} 3, \mathrm{CD} 4$, or $\mathrm{CD} 8$ at the 3-month point, there was no significant difference. However at 1 year after thymectomy, patients showed a significantly decreased percentage of CD3 and CD4 T cells $(p<0.01)$. CD8 cells were not significantly reduced. It should be noted that the reduction in CD3 did not approach the critically low level of approximately $20 \%$, which has been associated with a significant increase in clinical infections.

It is of interest that T-cell subset decreases were more marked for CD4 than for CD8 T cells. To test whether this reduction in the CD4 subpopulation was due to decreased production of new $T$ cells, six patients had determination of the percentage of 
Table III. Percent of lymphocytes by immunophenotype

\begin{tabular}{|c|c|c|c|c|c|}
\hline \multirow[b]{3}{*}{ Surface antigen } & \multicolumn{5}{|c|}{ Patient population } \\
\hline & \multicolumn{4}{|c|}{ Thymectomy (\%) } & \multirow[b]{2}{*}{ Control (\% } \\
\hline & Before operation & 3 Months & & 12 Months & \\
\hline CD3 & $65.2 \pm 2.9$ & $64.8 \pm 3.5$ & & $48.2 \pm 2.5^{*}$ & $64.4 \pm 2.1$ \\
\hline $\mathrm{CD} 4$ & $47.4 \pm 2.6$ & $46.6 \pm 2.6$ & & $30.8 \pm 2.4^{*}$ & $46 \pm 1.9$ \\
\hline $\mathrm{CD} 8$ & $20.3 \pm 4.2$ & $19.8 \pm 7.3$ & & $15.5 \pm 1.4$ & $17.5 \pm 1.4$ \\
\hline $\mathrm{CD}_{4 \mathrm{CD}} 45 \mathrm{RA}^{+}$ & \multirow{2}{*}{\multicolumn{4}{|c|}{$\begin{array}{l}49.8 \pm 7.6 \\
223+4.5\end{array}$}} & $59.7 \pm 6.4$ \\
\hline $\mathrm{CD}_{4 \mathrm{CD}} 45 \mathrm{RO}^{+}$ & & & & & $21 \pm 3.2$ \\
\hline
\end{tabular}

All data given as mean \pm SEM.

${ }^{*} p=<0.01$.

Table IV. Blastogenesis to mitogen PHA

\begin{tabular}{cccc}
\hline PHA & \multicolumn{3}{c}{ Thymectomy patients } \\
\cline { 2 - 4 } $\begin{array}{c}\text { concentration } \\
(\mu / \mathrm{ml})\end{array}$ & Before operation & 3 Months & 12 Months \\
\hline 100 & $105.6 \pm 8.4$ & $132.2 \pm 10.9$ & $140.9 \pm 8.9$ \\
20 & $94.6 \pm 11.2$ & $139.3 \pm 13.5$ & $123.0 \pm 10.1$ \\
\hline
\end{tabular}

Normal value $>75 \times 10^{3}$.

Data given in counts per minute $\times 10^{3}$ mean \pm SEM.

CD4, CD45, $\mathrm{RA}^{+}$and CD4, CD45, $\mathrm{RO}^{+}$cells. As shown in Table III, the percentage of CD4 lymphocytes that were recent thymic emigrants although slightly less than control was not significantly decreased $(p=0.356)$. Thus there was no significant decrease in the production of new CD4 T cells, in spite of a surgically "complete" thymectomy.

Response to PHA. Lymphocytes from patients who had undergone thymectomy showed a normal response to the mitogen PHA. These results (Table IV) are expressed as counts per minute $\times 10^{3}$.

Response to tetanus toxoid. The patients' lymphocytes were tested for their response to tetanus toxoid at 3 months, after all infant immunizations. At 3 months there were three patients who showed decreased responses $(<3 \times 103)$. However, by 1 year, all patients had normal responses. The results of these analyses are summarized in Table V. A cumulative frequency distribution plot has been included in Fig. 1.

Antibody titer to tetanus toxoid. To test for the normal interaction between $\mathrm{T}$ and $\mathrm{B}$ lymphocytes, the antibody response to tetanus toxoid was measured in the patients at 3 months and 1 year after the thymectomy. Although the titer of one patient was low at 3 months, it normalized by 12 months. Results are noted in Table VI, and a cumulative frequency distribution plot is shown in Fig. 2.

Clinical course. Through the first year of life, none of the study patients required hospital admis-
Table V. Blastogenesis to tetanus toxoid

\begin{tabular}{ccrc}
\hline Patients & Median & $95 \%$ CI & $\begin{array}{c}p \text { Value } \\
\text { (versus control) }\end{array}$ \\
\hline Thymectomy & & & \\
3 Months & 16.0 & 9,34 & 0.3656 \\
12 Months & 23.5 & 7,33 & 0.4622 \\
Controls & 30.0 & 10,42 & \\
\hline
\end{tabular}

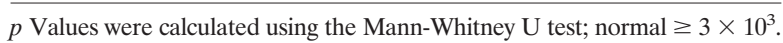

sion because of infection. There were the usual and expected number of minor infectious illnesses, which included incidents of conjunctivitis, sinusitis, otitis, and bronchitis, most of which were treated with outpatient antibiotics. The median number of events per patient was three $(95 \%$ CI 1,4). In particular, there was not an increased incidence of "thrush," generally considered to be the "hallmark" of T-cell immunodeficiency.

There was no correlation between the number of infectious incidents and the degree of reduction in $\mathrm{T}$ cells (total), T-cell subsets, or response to PHA and tetanus.

\section{Discussion}

There is a naturally occurring model of thymic deficiency that occurs in the DiGeorge syndrome. . $^{4-6}$ This is due to developmental anomalies of the third and fourth pharyngeal pouches and results in hypoplasia or aplasia of the thymus and parathyroid glands. Because the amount of thymic tissue that develops in the DiGeorge syndrome is variable, there is a spectrum of clinical immunologic manifestations. The degree of immunopathy correlates with the percentage of $\mathrm{T}$ cells. When the T-cell count drops to $10 \%$ to $15 \%$ of lymphocytes, there is usually an increase in infections, particularly candidiasis; if $\mathrm{T}$ cells reach $5 \%$ or less, life-threatening infections can occur. It should be noted that although there was some decrease in $\mathrm{T}$ cells in our 


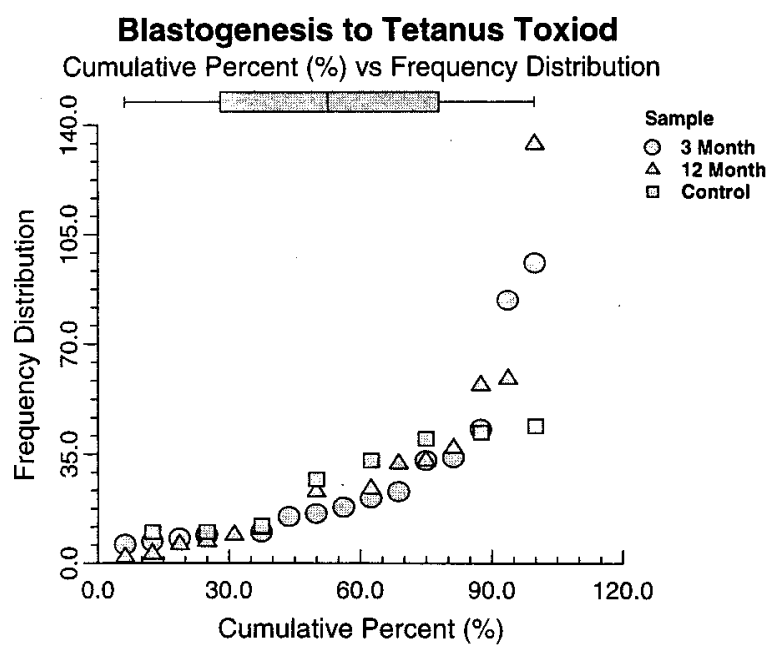

Fig. 1. This graph of blastogenesis to tetanus toxiod (cumulative percent versus frequency distribution) shows no significant difference in cumulative percentiles of frequencies of counts per minute in thymectomy and control patients at 3 and 12 months.

Table VI. Tetanus antibody in patients who had undergone thymectomy

\begin{tabular}{lccc}
\hline $\begin{array}{c}\text { After } \\
\text { thymectomy }\end{array}$ & Median & $95 \%$ CI & $\begin{array}{c}p \text { Value } \\
\text { (3-month vs 12-month) }\end{array}$ \\
\hline 3 Months & 0.31 & $0.05,1.00$ & 0.1998 \\
12 Months & 0.83 & $0.27,4.80$ & \\
\hline
\end{tabular}

$p$ Values were calculated with the Mann-Whitney $\mathrm{U}$ test; normal $\geq 0.1$ I.U.

neonates who had undergone thymectomy, none of them approached the theoretically critically low level of $20 \%$.

Although there is still uncertainly about exactly what point in time thymectomy might alter immune function, there are a number of studies that have addressed the issue. In landmark studies reported in 1961, Miller and associates ${ }^{7,8}$ showed that thymectomy in neonatal mice led to immunodeficiency, principally affecting cell-mediated immune response. It was subsequently shown that thymectomy in older children ( $>6$ months of age) and adults has no effect on immunity. ${ }^{1,2}$ It might be speculated that the difference between rodent and human immune outcomes after neonatal thymectomy relate to the relative level of gestational maturity at the time of birth. Because rodents are less mature when born, neonatal thymectomy might be expected to have a greater impact on immune function. In the only

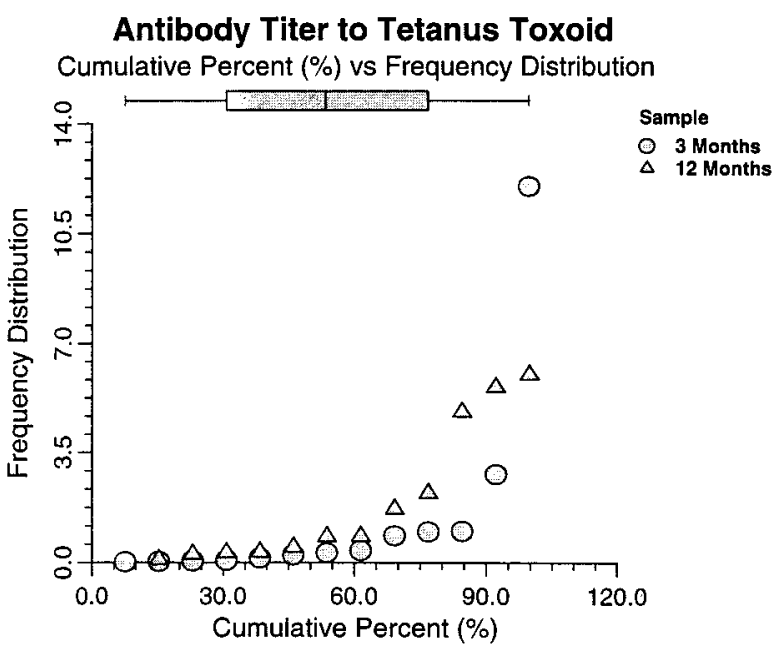

Fig. 2. This graph of antibody titer to tetanus toxoid (cumulative persent versus frequency distribution) shows no significant difference in cumulative percentiles in antibody response to tetanus toxoid in patients after thymectomy at the 3- and 12-month follow-up.

report that has focused on the effect of neonatal thymectomy in human beings, Brearley and associates $^{3}$ concluded that, although the clinical consequences of early thymectomy were unclear, there was evidence of impaired immunity as measured in later infancy. In this retrospective study, the authors documented a decreased number of $\mathrm{T}$ cells and T-cell subsets that were significantly lower than age-matched controls (as in this study) but did not approach the critically low value of $20 \%$ of lymphocytes as T cells. Although previous work by Hisatomi and associates ${ }^{9}$ had suggested that cardiopulmonary bypass (in adults) caused a transient decrease in T-cell subsets and PHA response lasting approximately 1 week, there was no such evidence in the study conducted by Brearley and associates ${ }^{3}$ for control patients who had not undergone thymectomy and who had had heart surgery when measured at the later interval of 9 to 36 months after the operation. Brearley and associates also found a marginally diminished response to PHA at the lowest dilution of $4 \mu \mathrm{g} / \mathrm{ml}$. In our laboratory, most control patients respond maximally to a PHA dilution of $20 \mu \mathrm{g} / \mathrm{ml}$. Maximal stimulation has not been seen at lower doses such as $4 \mu \mathrm{g} / \mathrm{ml}$. In normal patients, the response to PHA at $4 \mu \mathrm{g} / \mathrm{ml}$ has been erratic and not predictive of immune function. We did, in fact, test some of our study and control patients with the lower concentration of $4 \mu \mathrm{g} / \mathrm{ml}$ and 
found minimal responses in both control and study patients. Despite the subtle evidence of decreased immune function and no evidence of an increased incidence of infections, Brearley and associates ${ }^{3}$ concluded that thymectomy in pediatric cardiac surgery should be avoided. They advocated splitting the thymus vertically so that it could be held back by pericardial sutures or, if thymectomy was required, they suggested a partial excision. On the basis of our study, we do not concur. Removal of the thymus provides significantly better exposure, and splitting or partial resection of thymic tissue often results in a hemorrhagic gland that may be a source of continued bleeding.

The present study suggests that there must be tremendous redundancy or reserve built into the thymus. Despite what was a surgically "complete" resection of the encapsulated neonatal thymus, including the upper poles that extend into the cervical area, there was a relatively small effect on $\mathrm{T}$ cells. Most surprisingly, in the patients in whom the number of new thymic emigrants (CD4, CD45, and $\mathrm{RA}^{+}$) were tested, there was no evidence that thymectomy led to a decrease in the number of newly formed, naive $\mathrm{T}$ cells. The continued production of new T cells suggests that retained portions of the thymus, however small, are capable of maintaining adequate $\mathrm{T}$-cell production.

The thymus normally undergoes involution, and by the second decade of life the number of recent thymic emigrants (CD4, CD45, and $\mathrm{RA}^{+}$) begins to significantly decrease. ${ }^{10}$ The difference in the appearance of the pediatric versus adult thymus gland as seen at sternotomy is consistent with this decrease. The significance of the diminished capacity to produce new thymic $\mathrm{T}$ cells is not entirely clear, but it could be speculated that the increased susceptibility of some elderly individuals to new pathogens, such as new strains of influenza, may be related to their inability to produce new CD4, CD45, and $\mathrm{RA}^{+}$ cells. Given this possibility it remains to be seen whether patients who have had neonatal thymectomy will more rapidly lose their ability to produce new $\mathrm{T}$ cells (accelerated thymic involution) and what the impact on their immunity will be later in life.

\section{Limitations of the study}

Lack of "true" controls. Because surgical exposure would be significantly compromised without thymectomy, it was not deemed appropriate to prospectively randomize neonates undergoing cardiac repair into thymectomy and no thymectomy groups. The possibility of leaving a portion of the thymus gland was considered. However, this was believed to be undesirable because of bleeding issues but could have been a second arm to a future study if "complete" thymectomy had proved deleterious to immune function.

Lack of ability to measure retained thymus. Although the entire encapsulated thymus was removed (including the upper poles extending into the base of the neck), there is no way to determine how much thymic tissue remained. On the basis of our ability to visualize the mediastinal portion of the thymus at sternotomy, we would speculate that the retained portion was in the neck although there could be small detached thymic rests near the phrenic nerves where extensive dissection is avoided. It is also possible that there was significant thymic regeneration from small retained "rests" of tissue. However, our experience with staged reoperation, which was carried out in a small number of the patients, did not reveal an anatomically identifiable thymic structure.

Length of follow-up. We have demonstrated no significant defects in immune function in the present study. A longer follow-up would provide information on the persistence of the trend toward lower T-cell counts and the natural history of thymic involution in these patients. It is our intent to continue the follow-up.

We thank Earl Leonard (MS, Biostatistics) for his help with statistical analysis of the data.

REFERENCES

1. Moretta L, Mingari MC, Webb SR, Pearl ER, Lydyard PM, Grossi CE, et al. Imbalances in $\mathrm{T}$ cell subpopulations associated with immunodeficiency and autoimmune syndromes. Eur J Immunol 1977;7:696-700.

2. Rubenstein A, Pelet B, Schwajen V. Immunological decay in thymectomized infants. Helv Paediatr Acta 1975;30:425-33.

3. Brearley S, Gentle TA, Baynham ID, Roberts DK, Abrams LD, Thompson RA. Immunodeficiency following neonatal thymectomy in man. Clin Exp Immunol 1987;70:322-7.

4. Lischner HW, Dacou C, DiGeorge AM. Normal lymphocyte transfer (NLT) test: negative response to a patient with congenital absence of the thymus. Transplantation 1967;5: 555-7.

5. Lischner HW, Punnett HH, DiGeorge AM. Lymphocytes of extrathymic origin from an infant with congenital absence of the thymus: behavior in vitro. Nature (Lond) 1967;214:580-3.

6. DiGeorge AM. Immunologic deficiency diseases in man. In: Bergsma D, editor. Birth Defects Orig Artic Ser 1968;4:11621.

7. Miller JF. Immunological functions of the thymus. Lancet 1961;2:748-9.

8. Miller JF, Doak S, Cross AM. Role of the thymus in recovery 
of the immune mechanism in the irradiated adult mouse. Proc Soc Exp Biol Med 1963;112:785-92.

9. Hisatomi K, Isomura T, Kawara T, Yamashita M, Hirano A, Yoshida $\mathrm{H}$, et al. Changes in lymphocyte subsets, mitogen responsiveness, and interleukin-2 production after cardiac operations. J Thorac Cardiovasc Surg 1989;98:580-91.

10. Mackal CL, Fleisher TA, Brown MR, Andrich MP, Chen CC, Feurersten IM, et al. Age, thymopoiesis, Arj CD4+ Tlymphocyte regeneration after intensive chemotherapy. N Engl J Med 1995;332:143-9.

\section{Discussion}

Dr. Steven R. Gundry (Loma Linda, Calif.). I congratulate Dr. Wells and his coauthors on a very nicely designed and presented study about a question that has worried most congenital heart surgeons since the onset of congenital heart surgery; that is, what to do with a thymus in your way and does it have any consequences. As most of us surgeons know, when something is in our way we usually throw it away and then worry about the consequences later. It is a delight to find some real science placed on this quite puzzling question.

In infant pediatric cardiac transplantation, we have believed that the elimination of the thymus and perhaps its $\mathrm{T}$ cells may have an effect on the early T-cell-mediated rejection of the new allograft. However, we have been disappointed in our large series at Loma Linda to find that T-cell-mediated rejection, despite a total thymectomy in all of our patients, is the predominant form of rejection. T-cell-mediated rejection is only slightly less vigorous than in a corresponding adult cardiac transplantation population. So we too have been unable to prove that thymectomy is beneficial for us in transplantation or, for that matter, negatively affects immune function.

Also, we have been surprised, often times greatly, by the regrowth of thymic tissue that we have found during those few occasions when retransplantation is necessary. During your few reoperations on patients, have you, in fact, rediscovered thymic tissue at the time of the operation?

I have only two questions. First, was the total thymectomy done by pulling both lobes of the thymus out of the neck or were the actual superior aspects of these lobes visualized directly?

Second, you point out in your article that the control patients did not have cardiac surgery. Perhaps the author could speculate as to the effect of cardiopulmonary bypass, in and of itself, on immune function and T-cell population apart from removal of the thymus.

Dr. Wells. Your first question concerns regrowth of the thymus seen at the time of a reoperation. In the moderate number of patients who have undergone staged procedures, we have not seen a significant amount of thymic tissue at the time of resternotomy.

Your second question involved the extent of the thymectomy and particularly the superior aspect of the thymic lobes as they extend into the cervical area. We have found that it is easiest to remove the neonatal thymus if you take all of the encapsulated tissue including its cervical extensions. By pulling the superior poles downward, you can usually identify and ligate the small vessels that enter the gland from the neck. The fact that we have made an effort to remove all of the encapsulated tissue may account for the lack of thymus as seen at reoperation, yet we speculate that there must be residual small rests of thymus to account for the presence of the CD4, CD45, and $\mathrm{RA}^{+}$(recent thymic emigrants) identified in our patients after thymectomy. These residual thymic sites would most likely be high in the neck or laterally along the area of the phrenic nerves, where our dissection tends to be less aggressive.

Finally, there was a question on the effect of cardiopulmonary bypass on T-cell populations and immune function. We have not done these studies; and although I doubt that there would be an effect, particularly months after the procedure, it would not be difficult to get these controls.

\section{Availability of Journal back issues}

As a service to our subscribers, copies of back issues of The Journal of Thoracic and Cardiovascular Surgery for the preceding 5 years are maintained and are available for purchase from Mosby at a cost of $\$ 16.00$ per issue until inventory is depleted. The following quantity discounts are available: $25 \%$ off on quantities of 12 to 23 , and one third off on quantities of 24 or more. Please write to Mosby, Inc., Subscription Services, 11830 Westline Industrial Drive, St. Louis MO 63146-3318, or call 800-453-4351 or 314-453-4351 for information on availability of particular issues. If unavailable from the publisher, photocopies of complete issues may be purchased from UMI, 300 N. Zeeb Rd., Ann Arbor, MI 48106, 313-761-4700. 